should become apparent. If this is not so, the most valuable aspect of the survey-that of giving warning of 'incipient malnutrition'-is being entirely lost. If the survey is being used for this purpose, the next important question is how much reliance can be placed upon the evidence so provided.

The report states that "in 1955 no sub-group fell below 95 per cent (of the estimated requirements) in energy value, but perecntages less than 95 were recorded in certain sub-groups for protein, calcium, iron and riboflavin". As the figures represent averages for groups of families, it must be supposed that some families within the groups had intakes considerably below the average 95 per cent. Did such families show any evidence of a deficiency of these particular nutrients? This is apparently not known. For young childless couples in the highest income group the energy value of the recorded diet was 143 per cent and the protein content 150 per cent of the recommended allowances; fat intakes were of the order of 150 grams per head per day. Are these people suffering from their over-indulgence, or should these levels be taken as evidence of incipient malnu. trition? At the moment, no one seems to know. For the whole ten thousand families, the caloric value of the diet averaged 105 per cent of the estimated requirement. If food intakes are regularly greater than requirements, body-weights in Great Britain should be steadily increasing. If they aro not doing so, then either the estimate of requirements is too low or the assessment of the diet is inaccurate.

It is sometimes forgotten that these records deal only with the quantities of food bought for domestic consumption in the course of the survey week; they do not set out to measure the actual quantity of food eaten by the families concerned. In attempting to assess the adequacy of the diets, arbitrary allowances are made for preparation waste, and a round ten per cent deduction is made for edible material discarded or given to pet animals; meals out are given a 'points' value of breakfast 4 , dinner 5 , tea 3 , and supper 2. It is unlikely that these 'corrections' are equally suitable for all families, all seasons, and all geographical areas. No attempt is made to allow for sweets, alcoholic or soft diınks, ice-creams, etc., nor are changes in larder stocks recorded-as they were when the survey first began. The arbitrary allowances made for cooking losses of thiamine and ascorbic acid, and the low vitamin A value assigned to carotene. rich foods are 'corrections' of questionable value. In all, there is room for a quite considerable degree of error when the analysis is confined to small subgroups, though the broad general picture obtained may be true enough.

The yardstick against which the recorded diets are measured for adequacy is the set of allowances recommended by a Committee of the British Medical Association in $1950^{1}$; but in making theso recommendations the Committee continually reiterated the 'urgent need' for further extensive study of human nutritional requirements. The failure to parallel the Food Survey with a clinical survey to assess the nutritional state of the consumers of diets of different level means that a most valuable opportunity to forward our knowledge of dietary needs is being entirely missed. As it stands, the Survey provides a mass of interesting detail on price trends, dietary patterns, seasonal, occupational and geographical influences, the effect of family size within different income groups, etc.; but it fails to make any contribution to tho knowledge most urgently needed, which relates to what type of diet is best and to what the range of nutrient intake is within which good health can be maintained.

At any time, a food consumption study is of little practical value unless it is made in conjunction with a study of the resultant health of the consumers ; at the present time, when such fundamental changes are being introduced into the methods of producing and processing our everyday foods, this second study is of paramount importance and it is to be hoped that future reports will include a section on the nutritional state of the families eating the diets described in so much detail.

M. W. Grant

${ }^{1}$ Report of the Committee on Nutrition. British Medical Association $(1950)$.

\section{RESEARCH ON ROADS IN BRITAIN}

$T$

HE annual reports of the Road Research Board of the Department of Scientific and Industrial Research and the Director of Road Research for the year 1956 have now appeared*.

The report of the Road Research Board directs attention to the growing road traffic problem and states that a method of evaluating road projects in relation to their economic advantages is to be tried. The importance of training road engineers in traffic engineering and the value of 'before and after' studies with the current road-building programme are emphasized. It is believed that the economic advantages of building new roads have been grossly under-estimated hitherto.

It is suggested that improvement of the facilities for studying the causes and means of reducing accidents is urgent. Closer attention should be paid to the contribution of high speed to the increase in road casualties, because "it may well be that neither the skill of the average driver nor the care normally bestowed on the maintenance of cars is commensurate with their high performance".

The report of the Director of Road Research summarizes the activities of the Road Research Laboratory during 1956 ; these come mainly under three headings : safety, traffic and materials and methods of construction.

Work on road safety has included tests and recommendations on protective helmets for motor-cyclists. Accident studies have been made with the object of designing safety devices for vehicles, such as interior padding and safety belts. The contribution of the nature of road surfaces to skidding accidents has been investigated; it is estimated that the reduction of accidents due to treating road surfaces at dangerous sites represents a saving of ten times the cost of maintaining the surface with a high resistance to skidding. Statistics of accidents due to various causes have been compiled and are summarized in the report. Vehicle- and road.lighting studies have been made with the object of finding economical methods of reducing accidents due to conditions of night driving.

Traffic statistics are being compiled annually, and detailed surveys of traffic in selected areas are made.

* Road Research 1956 : The Report of the Road Research Board with the Report of the Director of Road Research. Pp. iv $+88+$ 
Statistics indicate that in rural areas the average speed of traffic is increasing annually by approximately 1 m.p.h., and during 1956 the average speed of private motor-cars under normal conditions was between 45 and 50 m.p.h., goods vehicles being some 5-10 m.p.h. slower. Economic studies of road improvements are an important feature of the work of the laboratory on the traffic problem.

The section on materials and methods of construction contains accounts of experiments on alternative types of road construction, including foundation aspects such as soil moisture and drainage, soil compaction and soil stabilization. Experiments on concrete have been carried out in connexion with the behaviour of high-strength road surfaces: the mechanism of the cracking of concrete and means of achieving a reduced modulus of elastieity without reduced strength, to lessen the liability to cracking, have been investigated. The use of prestressed concrete for road construction has also been investigated. For this to be feasible, the friction between the foundations and the necessarily long concrete slabs must be such that stresses due to thermal effects are not excessive ; the difficulty of achieving this has properties and behaviour of bituminous road materials have been carried out with particular reference to anti-skid properties and durability.

Miscellaneous investigations have included the use of radioactive techniques for measuring the density of concrete slabs and the moisture content of soil in situ.

Salient features of some full-scale road experiments are given in an appendix.

T. M. Charlton not yet been overcome. Investigations into the

$-120 \mathrm{~km}$. $/ \mathrm{sec}$. in the northern leg and $+360 \mathrm{~km}$. $/$ sec. in the southern leg.

Among other points dealt with in the paper, reference may be made to the study of the profiles of the Balmer lines at Edinburgh, which indicated a kinetic temperature for the filaments of $10,000^{\circ}$ $15,000^{\circ} \mathrm{K}$., and are consequently cool regions embedded in the corona itself at a temperature of $10^{\circ} \mathrm{K}$. It has been suggested by F. Hoyle that the higher density and lower temperature in the filaments are maintained by a local magnetic field, which compresses the hot material and cools it sufficiently for the hydrogen atoms to radiate in the Balmer lines. If this occurs, then there must be a great release of magnetic energy during the 2-hr. blow-off phase, and it is extremely improbable that the same material which has blown away into space should return precisely to its original site. In conclusion, Dr. Ellison suggests that such high-speed projection of prominence material may well be associated with the generation of radio-waves of frequencies appropriate to the various levels. There is also the possibility of geomagnetic effects occurring on the Earth after a suitable travel-time in those cases where the blow-off occurs near the centre of the solar disk. It is therefore desirable that all blow-off filaments should be recorded and classified at solar observatories during the International Geophysical Year. A simple scheme of elassification has been proposed by Ohman, for inclusion in the Geophysical Year Solar Patrol Forms, and the hope is expressed that this classification will be generally adopted.

\section{BROOKHAVEN NATIONAL LABORATORY}

\section{A SOLAR 'BLOW-OFF' PROMINENCE}

$\mathrm{T}$

HE solar 'blow-off' prominence of May 18, 1956, and its possible effects are described by Dr. M. A. Ellison in two recent papers (Mon. Not. Roy. Astro, Soc., 116, 6; 1956, and The Observatory, 77, 896 ; 1957). This prominence was one of a number generated during February-April 1956 in the highly active centres of the northern solar hemisphere, and it had been followed across the Sun's disk as a typical quiescent dark filament before it blew-off at the west limb on May 18. The observations relating to this blow-off prominence were made with the combined spectrohelioscope and spectrograph and are discussed in the Monthly Notices. A height diagram plotted from measurements made at Edinburgh and Meudon (the latter were supplied by L. d'Azambuja from spectroheliograms) shows the rapid outward acceleration, and before $15 \mathrm{~h}$. $00 \mathrm{~m}$. the outward velocity along the solar radius was $20 \mathrm{~km}$. $/ \mathrm{sec}$. after $16 \mathrm{~h} .07 \mathrm{~m}$. it exceeded $600 \mathrm{~km}$. $/ \mathrm{sec}$. Calibrated plates of the $\mathrm{H} \alpha$ line were taken at $16 \mathrm{~h}$. $01 \mathrm{~m}$. and 16h. $04 \mathrm{~m}$. with the slit of the spectrograph crossing the arch at a mean height of $88 \times 10^{3} \mathrm{~km}$. above the limb. The plates were calibrated immediately afterwards in the spectral light from the centre of the solar disk, thus providing means of deducing the $\mathrm{H} \alpha$ brightness of the various points of the prominence which were traversed by the slit. These are tabulated as fractions of the centre of the disk continuum at a wave-length $15 \mathrm{~A}$. outside the Fraunhofer $\mathrm{H} \alpha$ line. The Doppler shifts on these plates gave components of velocity in the line of sight ranging between
$\mathrm{HE}$ Brookhaven National Laboratory, which is located at Upton, Long Island, about seventy miles east of New York City, was established in 1947 and is operated by a private institution, Associated Universities, Inc., under contract with the United States Atomic Energy Commission. The board of trustees comprises one scientist and one administrator from each of the nine sponsoring universitiesColumbia, Cornell, Harvard, Johns Hopkins, Massachusetts Institute of Technology, Princeton, Pennsylvania, Rochester and Yale. The director of the Atoms for Peace Digest for June 15 (3, No. 1 ; 1957), the first of several numbers to be devoted to the description of the large American atomic research centres, deals with the work of Brookhaven National Laboratory. Later issues will deal with Oak Ridge, Argonne, and the smaller research establishments of the U.S. Atomic Energy Commission.

Research and development work at Brookhaven is carried out by eight major scientific departments, including the departments of physics, chemistry and biology and medicine. The cosmotron department is now operating the 'Cosmotron' particle accelerator in three shifts, five days a week, and the main study is that of the unstable particles, including heavy mesons and hyperons. An efficient method for the extraction from the 'Cosmotron' of an intense proton beam and its direction on to a liquid-hydrogen target placed outside the accelerator has been developed. The construction of a proton synchrotron was commenced in 1954; it will consist of a steel and copper Laboratory is Dr. L. J. Haworth. The issue of 